\title{
Katalitik Ozonlanmanın Doğal Organik Maddenin Yapısına ve Trihalometan Oluşturma Potansiyeline Etkisi
}

\author{
Alper Alver ${ }^{*}$, Ahmet Kılıç² \\ 1* Aksaray Üniversitesi, Teknik Bilimler Meslek Yüksekokulu, Çevre Koruma Teknolojileri Bölümü, Aksaray, Türkiye, (ORCID: 0000-0003-2734-8544), \\ alperalver@gmail.com \\ ${ }^{2}$ Aksaray Üniversitesi, Mühendislik Fakültesi, Çevre Mühendisliği Bölümü, Aksaray, Türkiye (ORCID: 0000-0002-2365-3093), akilic68@ @mail.com
}

(Ilk Geliş Tarihi 01 Şubat 2021 ve Kabul Tarihi 9 Nisan 2021)

(DOI: 10.31590/ejosat.888867)

ATIF/REFERENCE: Alver, A. \& Kılı̧̧, A. (2021). Katalitik Ozonlanmanın Doğal Organik Maddenin Yapısına ve Trihalometan Oluşturma Potansiyeline Etkisi. Avrupa Bilim ve Teknoloji Dergisi, (23), 601-607.

$\ddot{\mathbf{O z}}$

Konvansiyonel arıtma prosesleri ile yeterli oranda giderilemeyen sucul ortamdaki doğal organik maddenin (DOM) dezenfeksiyon/oksidasyon amacıyla kullanılan klorla reaksiyona girmesi sonucunda oksidasyon yan ürünleri (OYÜ) oluşmaktadır. DOM ile ozon arasındaki reaksiyonlar doğal organik maddenin alifatikliği ve aromatikliği gibi fiziko kimyasal özelliklerine bağlıdır. $\mathrm{Bu}$ çalışmada yüzey su kaynaklarındaki doğal organik maddeleri temsil eden humik asit çözeltilerinin katalitik ozonlanması sonucunda oluşan oksidasyon yan ürünlerinden trihalometanlar gaz kromatografi kütle dedektörü vasitasılyla kalitatif olarak tespit edilmiş ve okside olmuş organik maddelerin yapısal değişimi takip edilmiştir. $10 \mathrm{mg} / \mathrm{L}$ doğal organik maddenin nötral $\mathrm{pH}$ seviyelerinde $10 \mathrm{mg} / \mathrm{L}$ çözünmüş ozon ile birlikte $0,050 \mathrm{~g} / \mathrm{L}$ katalizör kullanımında 15 dk. sonunda ÇOK, $\mathrm{UV}_{220}, \mathrm{UV}_{254}, \mathrm{UV}_{272}$ ve TTHM'de sırasıyla $\% 76,00, \% 32,48, \% 21,32, \% 3,49$ ve $\% 52-62$ değişim meydana getirdiği belirlenmiştir. Sonuç olarak katalitik ozonlamanın doğal organik maddenin bağ yapsını bozarak aromatiğini alifatiğe dönüştürdüğü ve bir kısmını son ürüne okside ederek dezenfeksiyon yan ürünü oluşumunu azalttığı tespit edilmiştir.

Anahtar Kelimeler: Doğal organik madde, Katalitik ozonlanma, Oksidasyon yan ürünleri, Alifatik, Aromatik, Trihalometanlar.

\section{The Effect of Catalytic Ozonation on the Natural Organic Matter Structure and Trihalomethane Formation Potential}

\begin{abstract}
Oxidation by-products (OBP) are formed as a result of the reaction of natural organic matter (NOM) in the aquatic environment, which cannot be removed sufficiently by conventional treatment processes, with chlorine used for disinfection/oxidation. The reactions between NOM and ozone depend on the physicochemical properties of the natural organic matter, such as aliphaticity and aromaticity. In this study, trihalomethanes, which are formed as a result of catalytic ozonation of humic acid solutions representing natural organic substances in surface water resources, were qualitatively determined by gas chromatography-mass detector and the structural change of oxidized organic substances was followed. At neutral $\mathrm{pH}$ levels of $10 \mathrm{mg} / \mathrm{L}$ natural organic matter, $10 \mathrm{mg} / \mathrm{L}$ dissolved ozone and $0.050 \mathrm{~g} / \mathrm{L}$ catalyst use for 15 minutes. In the end, it was determined that it caused a change of $76.00 \%, 32.48 \%$, $21.32 \%, 3.49 \%$, and 52-62\% in DOC, $\mathrm{UV}_{220}, \mathrm{UV}_{254}, \mathrm{UV}_{272}$, and TTHM, respectively. As a result, it has been determined that catalytic ozonation transforms its aromatics into aliphatic by disrupting the bond structure of natural organic matter and reduces the formation of disinfection by-products by oxidizing some of it to the final product.
\end{abstract}

Keywords: Natural Organic Matter, Catalytic Ozonation, Oxidation By Products, Aliphatic, Aromatic, Trihalomethanes.

\footnotetext{
* Sorumlu Yazar: alperalver@gmail.com
} 


\section{Giriş}

Su kaynaklı hastalıkların azaltılması ve toplum sağlığını korumada 19. yy'ın sonlarından itibaren içme suyu dezenfeksiyon prosesleri kullanılmaktadır ( $\mathrm{Li}$ ve ark., 2016). İçme suyu arıtımının en önemli sorunlarından bir tanesi, tüm yüzeysel ve yeraltı su kaynakları bünyesinde bulunan doğal organik maddelerin (DOM) içme sularının dezenfeksiyonu amaciyla kullanılan oksidanlarla reaksiyonu sonucunda oksidasyon/dezenfeksiyon yan ürünlerinin (OYÜ ya da DYÜ) oluşmasıdır. $\mathrm{Bu}$ sebeple DOM'lar OYÜ öncüleri olarak isimlendirilmektedir. DOM'un oksidanlarla reaktivitesi, molekül ağırlığı, aromatikliği, elemental bileşimi ve içerdiği fonksiyonel gruplar gibi fiziko kimyasal özellikleri ile ilişkilidir (Maurice ve ark., 2002). DOM'lar, farklı fonksiyonel ve yapısal özelliklere sahip organik bileşiklerin heterojen karışımıdır ve iki ana sınıfa ayrılır: hümik ve hümik olmayan maddeler (Sadrnourmohammadi ve ark., 2020). Hümik maddeler, bitki ve hayvan dokularının bozunmasından kaynaklanan çeşitli organik maddeler grubu olarak tanımlanır ve bu sebeple bölgesel olarak oldukça farklılıklar gösterebilmektedir. Hümik maddeler, 2'den daha düşük pH seviyelerinde çözünmeyen bileşikler olan hümik asitlerden (HA) ve tüm $\mathrm{pH}$ seviyelerinde çözünebilen fulvik asitlerden (FA) oluşur (Brezinski Gorczyca, 2019).

Trihalometanlar (THM) ve Haloasetik asitler (HAA), bilinen oksidasyon yan ürünlerinin başlıca iki grubudur. Oksidasyon yan ürünleri, tehlikeli kirleticilerdir ve THM'ler ve HAA'lar gibi OYÜ'ler US EPA listesinde zehirli ve öncelikli tehlikeli kirleticiler olarak sınıflandırılmışlardır (Hayward, 1998). Dünya Sağllk Örgütü tarafindan bu OYÜ’lerin içme sularında varlığı için sınır değerler belirlenmiştir. Bilindiği üzere Avrupa Birliği; DYÜ'ler olarak tanımlanan THM'ler için Su Çerçeve Direktifinde (SÇD), verilen Çevresel Kalite Standartlarına (ÇKS) uyulmasını diğer kirleticiler için ise ülkelerin kendi belirledikleri ulusal ÇKS'lere uymasını beklemektedir. Ülkemizde de TSE-266 içme kalite standartlarında Toplam THM (TTHM) limit değeri $100 \mu \mathrm{g} / \mathrm{L}$ 'dir (Bakanlığı, 2012). THM harici diğer OYÜ’ler için ülkemizde henüz bir standart belirlenmemiştir. OYÜ ile ilgili yapılan bilimsel çalışmalar, bu zararlı bileşiklerin kanser oluşturma riski, çocuklarda gelişme geriliği, kadınlarda düşük yapma ve doğuştan meydana gelen kalp kusurları gibi hastalıklar ile yakından ilişkili olduğunu göstermiştir (Davies Mazumder, 2003). Toksisiteleri ve tehlikeli karakterleri ve çevre üzerindeki artan toplumsal kaygısı nedeniyle, içme suyu şebekesine karışmadan önce uzaklaştırılmaları gerekmektedir. Buna ilaveten, doğal organik maddelerin oksidanlarla reaksiyonlarının anlaşılabilmesi ile OYÜ oluşumunu azaltıcı yöntemler geliştirilebilecektir (Li ve ark., 2017).

Katalitik ozonlamanın su ve atık sulardaki dirençli kirleticileri bozunmada etkin olduğu kanıtlanmıştır. Katalitik ozonlama işlemi sırasında katalizörler, hidroksil radikallerinin üretilmesinde ve kirletici maddelerin ayrıştırılmasında önemli bir rol oynamaktadır. Sulardaki dirençli kirleticilerin bozundurulmasında doğrudan oksidasyon tek başına yetersiz kaldığından dolayı, oksidanın aktivitesini arttırarak dolaylı oksidasyonu başlatabilen $\mathrm{FeOOH}, \mathrm{Fe} / \mathrm{MgO}, \mathrm{TiO}_{2}$, pomza ve metal kompozitleri gibi birçok katalizör kullanılmaktadır (Gümüş Akbal, 2017). Katalizörlerin geliştirilmesinde ve kullanılmasında en önmeli göstergelerden biri kirleticiyi bozundurma işlevinin yanı sıra doğa dostu olması, ekonomik olması ve kolay tedarik edilebilmesidir. Bu sebeple yeni çevre dostu katalizörlerin aranması ve/veya katalizörün oksidanın etkinliğini arttırması için farklı metallerle kaplanması konularında birçok çalışma devam etmektedir. Kullanılan katalizörler arasında, Demir Kaplı Pomza'nın (DKP) doğal organik maddenin katalitik bozundurulmasında etkili olduğu kanıtlanmıştır.

Bu çalışmada yüzeysel sularda bulanabilecek doğal organik maddeleri temsilen Sigma Aldrich humik asitinden hazırlanmış model çözeltilerin farklı işletme şartlarında katalitik ozonlanması sırasındaki doğal organik maddenin fiziko kimyasal özelliklerinin değişimi ve bu değişime bağlı olarak ortaya çıkan oksidasyon yan ürünlerinden THM araştırılmıştır. Katalizör olarak DKP kullanılmıştır. Kataitilik ozonlamaya etkisi bilinen katalizör dozu, ozon dozu, başlangıç kirletici konsantrasyonu ve başlangıç çözelti pH'sı değişkenlerinin etkileri toplam organik karbon (TOK), $\mathrm{UV}_{220}, \mathrm{UV}_{254}, \mathrm{UV}_{272}$ ve TTHM analizleri ile izlenilmiştir. Laboratuvar çalışması neticesinde katalitik ozonlama prosesi değişkenlerine bağlı oluşabilecek TTHM miktarları belirlendiğinden çalışma çıktılarının içme suyu kaynaklarının seçimi ve arıtma tesisi tasarımında proses seçimi ve uygulanabilirliğini tayin etmede önemli rol oynayacağ düşünülmektedir.

\section{Materyal ve Metot}

\subsection{Malzemeler ve Kimyasallar}

Aksaray İli Hasan Dağı bölgesinde bulunan bir taş ocağından temin edilen pomza örnekleri öğütülerek parçalandıktan sonra elek analizleri ile $<0.25 \mathrm{~mm}$ tane boyutuna ayrılmış ve demirle kaplanarak ozonlama işlemlerinde kullanılmıştır. Lai ve ark. (2000) ve (Lai Chen, 2001) tarafından önerilen metod üzerinde yapılan bazı değişikliklerle kaplama işlemi gerçekleştirilmiştir. Bu metoda dair detaylı bilgiler önceki çalışmamızda verilmiştir (Alver ve ark., 2016).

Çalışmalarda yüzey sularını simüle etmek amacıyla doğal organik maddeleri temsilen hümik asit çözeltileri kullanılmıştır. Hümik asit (H16752) Sigma-Aldrich firmasından temin edilmiştir. Kristal haldeki hümik asit $0.1 \mathrm{~N}$ Sodyum hidroksit içerisinde 2 saat süreyle karıştırılarak çözüldükten sonra 0.45 $\mu \mathrm{m}$ membran filtre kağıdından süzülmüştür. Stok olarak hazırlanan bu çözeltiden, çalışmalarda kullanılmak üzere yüzey sularında tespit edilebilen konsantrasyonlarda hümik asit çözeltileri elde edilmiştir. Model çözelti olarak kullanılan Sigma Aldrich hümik asitinin karakterizasyonu Tablo 1'te verilmiştir.

Tablo 1 Humik asit çözeltilerinin karakterizasyonu

\begin{tabular}{lccc}
\hline Parametre & Denklem $(\mathbf{n = 4})$ & $\mathbf{R}^{\mathbf{2}}$ & $\begin{array}{c}\text { Algılama } \\
\text { Limiti }\end{array}$ \\
\hline $\mathrm{UV}_{220}$, Abs. & $0,0275 \times \mathrm{HA}+0,0380$ & 0,9997 & 0,0009 \\
$\mathrm{UV}_{254}$, Abs. & $0,0235 \times \mathrm{HA}+0,0209$ & 0,9995 & 0,0015 \\
$\mathrm{UV}_{272}, \mathrm{Abs}$. & $0,0211 \times \mathrm{HA}+0,0191$ & 0,9994 & 0,0018 \\
ÇOK, mg/L & $0,2089 \times \mathrm{HA}-0,0608$ & 0,9984 & 0,0048 \\
\hline
\end{tabular}

Çalışma kapsamında oksidasyon ürünlerinin tespiti amacıyla THM türleri izlenmiştir. THM analizleri için Restek firmasından temin edilen sertifikalı referans materyal (SRM) mix standartları, ekstraksiyon işlemlerinde ise Sigma-Aldrich firmasından satın alınan metil tert-butil eter (MTBE) kullanılmıştır. Suda çözünmüş ozon ölçümlerinde kullanılan potasyum indigo trisülfonat Sigma-Aldrich firmasından temin 
edilmiştir. Deneysel çalışmaların tüm aşamalarında analitik saflıkta kimyasallar seçilmiş ve çözeltiler ultra saf su kullanılarak hazırlanmıştır.

\subsection{Deneysel Prosedür}

Ozonlama deneyleri oda sıcaklığında $80 \mathrm{~mm}$ iç çaplı cam kolon reaktörde gerçekleștirilmiştir. Reaktör 2 L çözelti hacminde ve yarı kesikli sistemde çalıştırılmış, reaktör içeriğinin tam karışımı 600 rpm'de dönen mekanik bir karıştırıcı ile sağlanmıştır. Tüm deney düzeneği bağlantılarında ozonla reaksiyona girmeyen malzemelerin seçilmesine dikkat edilmiştir. Reaktöre beslenen ozon gazı, oksijen konsantratörü donanımlı ve $0.333 \mathrm{~g} / \mathrm{dk}$ ozon üretim kapasitesine sahip PRO DO 20 ozon jeneratörü (PRODA Group, Türkiye) ile üretilmiştir. Ozonun sudaki çözünürlüğünü artırmak ve istenilen konsantrasyonlarda çözünmüş ozon elde etmek için ozon beslemeleri reaktörün alt kısmından ve politetrafloroetilen (PTFE) malzemeden üretilmiş difüzör vasıtası ile yapılmıştır. Reaktörden çözünmeden çıkan gaz fazındaki ozonun tutulması için reaktörü takip eden ve içinde \%2'lik KI çözeltisi bulunan 2 adet gaz yıkama şişesi kullanılmıştır. Reaktöre istenilen konsantrasyonlarda hümik çözeltisi ilave edildikten sonra belirli zaman aralıklarında örnekler alınmış ve analizleri yapılmıștır. Analizlerden önce ozon reaksiyonlarını durdurmak amacıyla, alınan örneklere $0.025 \mathrm{M} \mathrm{Na}_{2} \mathrm{SO}_{3}$ ilave edilmiş ve $0.20 \mu$ m'lik bir filtreden süzülmüştür. Elde edilen filtratta çözünmüş ozon, TOK, $\mathrm{UV}_{220}$, $\mathrm{UV}_{254}, \mathrm{UV}_{272}$ ve Toplam THM analizleri yapılmıştır. Çözünmüş ozon analizleri JUMO AQUIS 500 AS ozon analizörü (JUMO Corp. Group, Almanya) ile ASTM D7677 metoduna (International, 2004) uygun olarak sürekli izleme yöntemiyle gerçekleştirilmiştir. Bu yöntemle yapılan ozon analizlerinin doğrulama çalışmaları reaktörden eş zamanlı alınan örneklerde $\mathrm{SM} 4500-\mathrm{O}_{3}$ B İndigo metodu ile ozon analizleri yapılarak gerçekleştirilmiştir.

\subsection{Analiz Yöntemleri}

Reaktörden alınan örneklerde $220 \mathrm{~nm}\left(\mathrm{UV}_{220}\right), 254 \mathrm{~nm}$ $\left(\mathrm{UV}_{254}\right)$ ve $272 \mathrm{~nm}\left(\mathrm{UV}_{272}\right)$ dalga boylarında absorbans ölçümleri SM 5910 B (Rice ve ark., 2012) metoduna uygun olarak yapılmıştır. Bu amaçla Shimadzu marka UV-1280 model UV-VIS spektrofotometre ve $10 \mathrm{~mm}$ 1şık yoluna sahip kuvars hücre kullanılmıştır. Doğal organik maddeler genel olarak hidrofobik özelliktedir. Doğal organik maddelerin oksidantlarla reaksiyonları sonucunda hidrofilik fraksiyonların da artış olmaktadır. $\mathrm{UV}_{254}$ değerinin hümik maddeler gibi yüksek moleküler ağırlığına sahip organik maddelerin hidrofobikliğinin ve alifatik içeriğinin tespitinde kullanılan önemli bir temsil edici parametre olduğu ortaya konulmuştur (Kim ve ark., 2006). $\mathrm{UV}_{220}$ değeri ise okside olmuş organik madde fraksiyonlarının molekül ağırlığı dağılımını göstermektedir (Świetlik ve ark., 2004). Bunun yanında $U_{272}$ değeri, DOM molekülü ile klor arasındaki reaksiyonlar sırasında fenolik ve hidroksil gibi fonksiyonel gruplar içeren aromatik yapıların bozulmasına karşılık DOM'nin UV absorbansında meydana gelen kayıpları göstermektedir (Chi-Wang ve ark., 1998). $\Delta \mathrm{UV}_{220}, \Delta \mathrm{UV}_{254}$ ve $\Delta \mathrm{UV}_{272}$ Denklem 1'e göre hesaplanmıştır.

$$
\Delta \mathrm{UV}_{x}=\frac{\mathrm{UV}_{x_{\text {başlangıç }}}-\mathrm{UV}_{x_{\text {zaman }}}}{\mathrm{UV}_{x_{\text {başlangıc }}}} \quad \text { Denklem 1 }
$$

Toplam organik karbon analizleri Standart Metotlar 3510 B'de tanımlanan yüksek sicaklıkta yakma metoduna göre
Shimadzu TOC-VCPN/TNM-1 cihazı kullanılarak yapılmıştır. Toplam organik karbon; toplam karbon ve inorganik karbon farkı alınarak hesaplanmıştır. ÇOK ölçümleri ise aynı metoda göre numuneler $0,45 \mu \mathrm{m}$ 'lik filtreden süzüldükten sonra gerçekleştirilmiştir.

Belirli aralıklarla reaktörden alınan ozonlama işlemine tabi tutulmuş örnekler, kalıntı ozon giderildikten sonra $\mathrm{Cl}_{2} / \mathrm{ÇOK}$ oranı 2,5 olacak şekilde sodyum hipoklorit çözeltisi ile klorlanmış ve oda sıcaklığında 168 saat boyunca inkübasyona bırakılmıştır. İnkübasyon süresi sonunda Sigma Aldrich Quantofix klor test kiti ile bakiye klor ölçümleri yapılmış ve ortamda bakiye klor varlığ teyit edilmiştir. Klorlama reaksiyonları teflon kapaklı sızdırmaz $40 \mathrm{~mL}$ 'lik viallerde gerçekleştirilmiştir. Analiz edilmek üzere 7,5 mL örnek 2,5 mL MTBE çözücüsü ile $45 \mathrm{dk}$. boyunca cam baloncuk ilave edilmiş bir cam şişe içerisinde BIOSAN Multi RS-24 programlanabilir rotator yardımıyla çalkalanmış ve faz ayrımı gerçekleştikten sonra $2 \mathrm{~mL}$ 'lik viallere aktarılmıştır. THM ölçümleri sıvı sıvı ekstraksiyon işlemi ile EPA 551.1 metoduna uygun olarak gerçekleștirilmiştir. Analizlerde RTX-624 $(60 \mathrm{~m} * 0.25 \mathrm{~mm} * 1.40 \mu \mathrm{m})$ kapiler kolona sahip Shimadzu QP2010 Plus model GC/MS cihazı kullanılmıştır. Cihazda enjeksiyon sıcaklığ1 ve detektör sıcaklığ $200{ }^{\circ} \mathrm{C}$; enjeksiyon hacmi $2 \mu \mathrm{L}$ ve akış hızı $61,1 \mathrm{~mL} /$ dak olarak ayarlanmış, taşıyıcı gaz olarak yüksek saflıkta helyum gazı kullanılmıştır. Örneğin enjeksiyonu splitless modda gerçekleştirilmiş ve $45{ }^{\circ} \mathrm{C}$ 'de enjekte edilen örnek bu sicaklıkta 3 dakika tutulmuştur. Ardından 3'er dakikalık bekletme süreleri ile sıcaklık önce $5{ }^{\circ} \mathrm{C} / \mathrm{dk}$ artışla 90 ${ }^{\circ} \mathrm{C}^{\prime}$ ye sonra $10{ }^{\circ} \mathrm{C} / \mathrm{dk}$ artışla $150{ }^{\circ} \mathrm{C}$ 'ye ve son olarak $5{ }^{\circ} \mathrm{C} / \mathrm{dk}$ artışla $220^{\circ} \mathrm{C}^{\prime}$ ye çıkarılmış ve bu sıcaklıkta $4 \mathrm{dk}$ tutulmuştur. Kullanılan metodun verifikasyonu amaciyla analizi yapılan THM türleri için geri kazanım çalışmaları yapılmış ve LOD değerleri tespit edilmiştir. Tablo 2'de verilen geri kazanım yüzdeleri ve LOD değerlerinin metot gereksinimlerini karşıladığı görüldükten sonra örneklerin analizleri yapılmıştır.

Tablo 2 THM'ler için geri kazanım yüzdeleri ve LOD değerleri.

\begin{tabular}{lcc}
\hline Bileşen & $\begin{array}{c}\text { Geri Kazanım }(\%) \\
(\mathbf{n}=\mathbf{1 0})\end{array}$ & $\begin{array}{c}\text { LOD } \\
(\boldsymbol{\mu g} / \mathbf{L})\end{array}$ \\
\hline Kloroform & $92,7 \pm 2,8$ & 0,41 \\
Boromodiklorometan & $96,3 \pm 1,9$ & 0,76 \\
Klorodibromometan & $93,4 \pm 1,5$ & 0,55 \\
Bromoform & $97,2 \pm 0,6$ & 0,76 \\
\hline Toplam THM & $92,7 \pm 2,2$ & 0,76 \\
\hline
\end{tabular}

\section{Araştırma Sonuçları ve Tartışma}

Bu bölümde, doğal organik maddenin katalitik ozonlanması sonrasında yapısal değişimi ve dezenfeksiyonu sonucunda oluşabilecek dezenfeksiyon yan ürünlerinden THM'lerin belirlenmesi için laboratuvar ölçekli çalışma gerçekleştirilmiştir. Katalitik ozonlamanın doğal organik maddenin alifatik ve aromatik yapısında oluşturduğu değişimi ve buna bağlı olarak THM oluşturma potansiyeli üzerindeki etkisini anlamak için model çözeltilerle çalışmalar yapılmıştır. Katalitik ozonlama sonrasında çıkış suları klorla reaksiyona tabi tutularak oluşan THM'ler, deiyonize saf su içeren ve sadece hümik asit içeren model çözeltilerde kalitatif olarak tespit edilmiş ve bu ürünlerde katalitik ozonlama koşullarına bağlı olarak değişimler gözlemlenmiştir. 


\subsection{Katalizör Dozunun Katalitik Ozonlamaya Etkisi}

Katalitik ozonlama deneyleri, 25 ila $100 \mathrm{mg} / \mathrm{L}$ arasında değişen çeşitli katalizör dozlarında, $10 \mathrm{mg} /$ L'lik HA konsantrasyonu, çözelti pH'1 6,8 ve ozon dozu 10 mg/L'lik sabit tutularak gerçekleştirilmiştir. Katalizör dozunun artışına göre oksitlenmiş organik maddenin ÇOK konsantrasyonundaki ve aromatik ve alifatik fraksiyonlarındaki değişimi Tablo 3'de verilmiştir.

Tablo 3 Katalizör dozuna bağll olarak ÇOK, UV $220, U V_{254}$ ve $U V_{272}$ değişimi $\left(\left[\mathrm{O}_{3}\right]=10 \mathrm{mg} / \mathrm{L},[\mathrm{HA}]=10 \mathrm{mg} / \mathrm{L}, \mathrm{pH}=6.8 \pm 0.4\right.$, $n=600 \mathrm{rpm}$ ).

\begin{tabular}{|c|c|c|c|c|}
\hline Katalizör, g/L & $\underset{\%}{\text { ÇOK, }}$ & $\begin{array}{c}\Delta \mathrm{UV}_{220}, \\
\%\end{array}$ & $\begin{array}{c}-\Delta \mathbf{U V}_{254}, \\
\%\end{array}$ & $\begin{array}{c}-\Delta \mathbf{U V}_{272}, \\
\%\end{array}$ \\
\hline 0,025 & 64 & 0,67 & 21,42 & 2,50 \\
\hline 0,050 & 76 & 32,48 & 21,32 & 3,49 \\
\hline 0,075 & 80 & 37,24 & 25,30 & 5,74 \\
\hline 0,100 & 87 & 59,81 & 79,57 & 21,21 \\
\hline
\end{tabular}

Tablo 3'deki sonuçlardan da görüldüğü üzere katalizör dozunun artışına bağlı olarak organik maddenin konsatrasyonu \%64'den \%87'ye kadar azalmıştır. Organik maddenin aromatik fraksiyonlarının alifatik fraksiyonlarına oranla daha hızlı bozunduğu ve okside olmuş fraksiyonunda doğrusal artış olduğu gözlenmiştir. $0.075 \mathrm{~g} / \mathrm{L}$ katalizör dozuna kadar $\mathrm{UV}_{220}, \mathrm{UV}_{254}$ ve $\mathrm{UV}_{272}$ değişiminin çok fazla olmadığı, $0.100 \mathrm{~g} / \mathrm{L}$ katalizör dozu uygulandığında ise önemli bir sıçrama yaptığı görülmektedir. Katalitik ozonlamada organik maddenin önce aromatik yapısının bozunup alifatiğe dönüştüğü ve bu dönüşüm sonrasında alifatik fraksiyonlarında oksitlenme sonucunda son ürünlere dönüşmüş olduğu düşünülmektedir. Bu sonuçlar Şekil 1'de verilen TTHM konsatrasyonlarının katalizör dozunun artışına bağlı olarak değişiminin verildiği grafikte daha iyi yorumlanmaktadır.

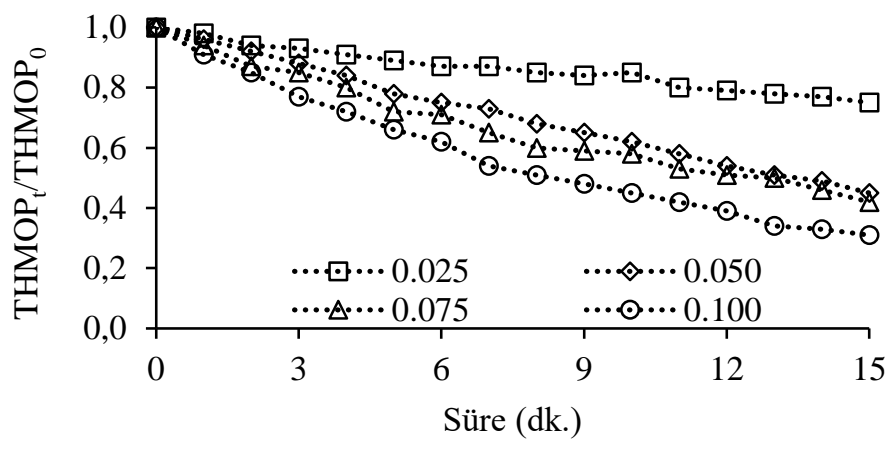

Şekil 1. Katalizör dozuna bağlı olarak THMOP azalımı $\left(\left[\mathrm{O}_{3}\right]=10 \mathrm{mg} / \mathrm{L},[\mathrm{HA}]=10 \mathrm{mg} / \mathrm{L}, \mathrm{pH}=6.8 \pm 0.4, n=600 \mathrm{rpm}\right.$, $\left.\left[\mathrm{THMOP}_{0}\right]=111,180 \pm 3,076 \mu \mathrm{g} / \mathrm{L}\right)$

Katalizör dozundaki artışa bağlı olarak $\mathrm{OH} \bullet$ oluşum hızı artmakta ve oluşan oksidasyon ara ürünlerinin $\mathrm{OH} \bullet$ ile reaksiyona girmesi sonucunda organik maddenin bir kısmı son ürüne $\left(\mathrm{CO}_{2}\right.$ ve $\left.\mathrm{H}_{2} \mathrm{O}\right)$ dönüşerek organik madde konsantrasyonlarında azalma sağlanmaktadır. Bu azalmaya bağlı olarakta THMOP azalmaktadır. Bu sonuçlar, Yuan ve ark. (2012) çalışmasında olduğu gibi DKP katalizörünün katalitik ozonlamada etkin olarak kullanılabileceğini ortaya koymaktadır. Son ürüne dönüşmeyen ozonlanmış organik madde yapısının klorla reaksiyonu sonucunda başlangıca nazaran daha az TTHM oluşturduğu da görülmektedir. Hem katalizör dozu hem de reaksiyon süresindeki artışla belirlenen TTHM konsantrasyonu azalmaktadır. Organik maddenin alifatik ve aromatik fraksiyonlarının bağ yapısının bozundurulması için $0,100 \mathrm{~g} / \mathrm{L}$ katalizör dozunun uygun olduğu tespit edilse de çalışmanın hedef kirleticisi olan THM türlerinin giderimi için $0,050 \mathrm{~g} / \mathrm{L}$ katalizör dozu optimum seviyededir.

\subsection{Başlangıç Ozon Dozunun Katalitik Ozonlamaya Etkisi}

Katatilik ozonlama proseslerinde uygulanan ozon dozu, DOM'un bozunma verimini etkileyen önemli faktörlerden biridir. Bu başlık altında $6,8,10$ ve $12 \mathrm{mg} / \mathrm{L}$ başlangıç ozon dozlarının katalitik ozonlama sürecine etkisi incelenmiştir. Başlangıç ozon konsantrasyonundaki artış, daha fazla radikal oluşturduğundan doalyı DYÜ'lerin azaltılması üzerinde olumlu bir etkiye sahiptir. Katalitik ozonlama sırasında oluşan radikallerin, oksidasyonu yavaş olan oksidasyon ara ürünlerini ve son ürünleri daha hızlı bozundurduğu düşünülmektedir. Başlangıç ozon dozu artışına bağlı olarak ÇOK, $\mathrm{UV}_{220}, \mathrm{UV}_{254}$ ve $\mathrm{UV}_{272}$ değişimleri Tablo 4'de verilmiştir.

Tablo 4 Ozon dozuna bağll olarak ÇOK, $U V_{220}, U V_{254}$ ve $U V_{272}$ değişimi $([D K P]=0.050 \mathrm{~g} / \mathrm{L},[\mathrm{HA}]=10 \mathrm{mg} / \mathrm{L}, \mathrm{pH}=6.8 \pm 0.4$, $n=600 \mathrm{rpm})$.

\begin{tabular}{lcccc}
\hline Ozon Dozu, mg/L & $\begin{array}{c}\text { ÇOK, } \\
\text { \% }\end{array}$ & $\begin{array}{c}\Delta \mathbf{U V}_{\mathbf{2 2 0}}, \\
\mathbf{\%}\end{array}$ & $\begin{array}{c}-\boldsymbol{\Delta} \mathbf{U V}_{\mathbf{2 5 4}}, \\
\mathbf{\%}\end{array}$ & $\begin{array}{c}-\boldsymbol{\Delta U \mathbf { U V } _ { 2 7 2 } ,} \\
\mathbf{\%}\end{array}$ \\
\hline 6 & 66 & 0.42 & 0,67 & 0,34 \\
8 & 66 & 14,00 & 2,37 & 3,02 \\
10 & 76 & 32,48 & 21,32 & 3,49 \\
12 & 81 & 93,43 & 59,81 & 7,37 \\
\hline
\end{tabular}

Tablo 3'deki sonuçlara benzer şekilde Tablo 4'te de aromatik yapının artan ozon dozu ile daha da bozulmuş olduğu görülmektedir. Ozon konsantrasyonunun 6 mg/L'den 10 mg/L'ye çıkmasıyla ÇOK giderim veriminin \%66'dan \%81'e yükseldiği görülmektedir. Bu çalışmada, ozonun sudaki davranışı üç temel unsura dayanmaktadır: moleküler ozonun HA ile doğrudan reaksiyona girerek harcanması, katalizör ara yüzeyinde ozonun ayrışarak radikallerin oluşması ve ozon moleküllerinin katalizör ve kirletici yüzeyinde kısa süreli adsorpsiyonu. Başlangıç ozon konsantrasyonunun HA'nın katalitik ozonlanması üzerindeki etkisi Şekil 2'de gösterilmektedir.

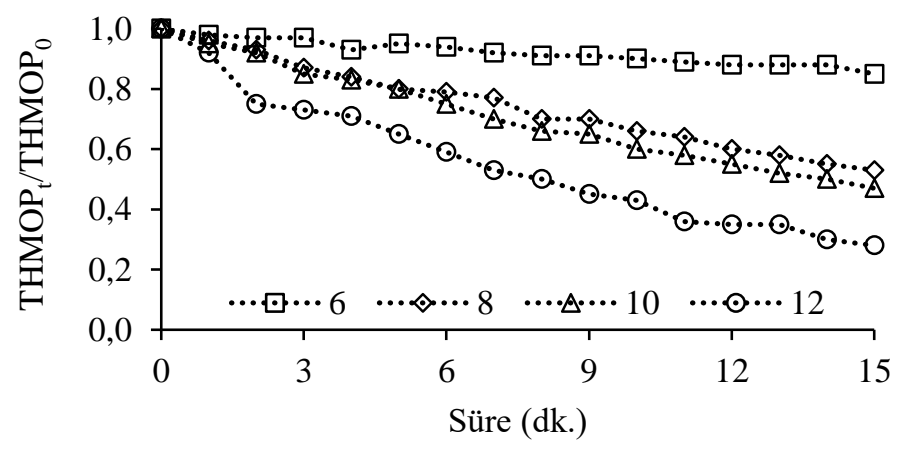

Şekil 2. Başlangıç ozon dozuna bağlı olarak THMOP azalımı $([D K P]=0.050 \mathrm{~g} / \mathrm{L},[\mathrm{HA}]=10 \mathrm{mg} / \mathrm{L}, \mathrm{pH}=6.8 \pm 0.4, n=600 \mathrm{rpm}$, $\left[\right.$ THMOP$\left.\left._{0}\right]=110,683 \pm 1,490\right)$

Ozonun bozunmaya başlama sürecinde yani ilk 2 dk.'da THMOP konsantrasyonları pek değişmemiştir. Bu sonucun, ozon 
dozundaki artıştan bağımsız olarak sabit $\mathrm{OH} \bullet$ oluşum hızından kaynaklandığı düşünülmektedir. Birim ozon dozu başına giderilen ÇOK ve THMOP göz önüne alındığında $10 \mathrm{mg} / \mathrm{L}$ başlangıç ozon dozunun optimum olduğuna karar verilmiştir.

\subsection{Kirletici Konsantrasyonunun Katalitik Ozonlamaya Etkisi}

Yüzeysel su kaynaklarında organik maddenin \%40-50'si fulvik asit ve \%5-10'u hümik asitten oluşmaktadır (Hong Elimelech, 1997). Su kaynaklarına göre organik madde fraksiyonları ve konsantrasyonları değişkenlik göstermekte bu nedenle standart bir metotla arıtılmaları zorlaşmaktadır. Katalitik ozonlama proseslerinin DOM giderim verimini etkileyen en önemli değişkenlerden biri kirletici konsantrasyonu ve karakterizasyonudur. Bu başlıkta, yüzeysel su kaynaklarında 0$20 \mathrm{mg} / \mathrm{L}$ konsantrasonyon aralığında bulunabilen konsantrasyonlarda doğal organik maddenin katalitik ozonlama sürecine etkisi araştırılmıştır. Başlangıç HA konsantrasyonuna bağlı olarak THMOP'deki değişim Şekil 3 'te verilmiştir.

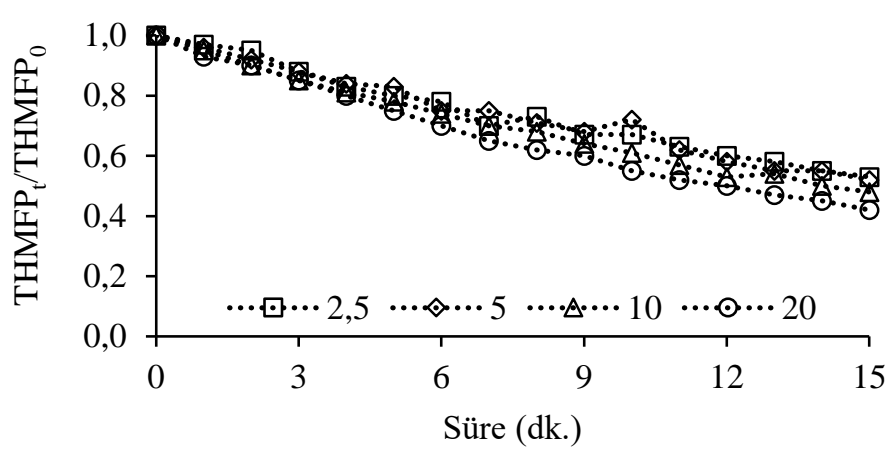

Şekil 3 Kirlietici konsantrasyonuna bağll olarak THMOP azalımı $\left([\mathrm{DKP}]=0.050 \mathrm{~g} / \mathrm{L},\left[\mathrm{O}_{3}\right]=10 \mathrm{mg} / \mathrm{L}, \mathrm{pH}=6.8 \pm 0.4, n=600\right.$ rpm), $\left[\text { THMOP }_{0}\right]_{2,5}=66,518,\left[\text { THMOP}_{0}\right]_{5,0}=79,332$,

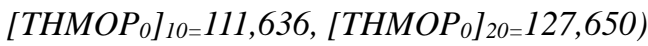

HA dozunun artmasiyla birlikte kütle transfer kuvveti armakta ve buna bağlı olarak katalizör yüzeyine adsorbe edilen HA moleküllerinin sayısı da artmaktadır. Buna sebeple HA konsantrasyonundaki bir artışa bağlı olarak giderim verimliliği azda olsa artış göstermektedir (Kim ve ark., 2013). Ancak katalizör yüzeyindeki aktif bölgelerin bir süre sonra dolması nedeniyle bu artış sınırlanmakta ve giderim verimi denge konumuna gelmektedir. Ayrica organik madde konsantrasyonundaki artışla birlikte katalizçr olarak kullanılan ve demir içeren pomza yüeyinde organometal kompleksleri oluşabilmekte ve ozonun tutunması için ayrı bir yüzey oluşturmaktadır. $\mathrm{Bu}$ nedenle radikal oluşumunun da kısmen yavaşladığı söylenebilir. Tablo 5'te ÇOK, $\mathrm{UV}_{220}, \mathrm{UV}_{254}$ ve $\mathrm{UV}_{272}$ parametrelerinin değişimi incelenmiş ve kirletici dozunun artması nedeniyle oksitlenen aromatik ve alifatik yapının benzer şekilde değiştiği görülmüştür.
Tablo 5 Başlangıç kirletici konsantrasyonuna bağlı olarak ÇOK, UV220, UV254 ve UV272 değişimi ([DKP]=0.025 $\mathrm{g} / \mathrm{L},[\mathrm{O} 3]=10$ $m g / L, p H=6.8 \pm 0.4, n=600 \mathrm{rpm})$.

\begin{tabular}{|c|c|c|c|c|}
\hline $\begin{array}{l}\text { HA Kons., } \\
\text { mg/L }\end{array}$ & $\begin{array}{c}\text { ÇOK, } \\
\%\end{array}$ & $\begin{array}{c}\Delta \mathbf{U V}_{\mathbf{2 2 0}} \\
\%\end{array}$ & $\begin{array}{c}-\Delta \mathbf{U V}_{254}, \\
\%\end{array}$ & $\begin{array}{c}-\Delta U_{2} V_{272} \\
\%\end{array}$ \\
\hline 2,5 & 64 & 23,43 & 17,97 & 2,10 \\
\hline 5 & 75 & 29,05 & 18,27 & 3,80 \\
\hline 10 & 77 & 32,48 & 21,32 & 3,49 \\
\hline 20 & 82 & 42,52 & 34,56 & 9,12 \\
\hline
\end{tabular}

Ozon ve organik karbon bileşikleri arasındaki reaksiyonların karbon bağlarının bir fonksiyonu olduğu bilinmektedir. Karbon bağları, elektron verici veya aromatik bileşikler içeren fonksiyonel gruplardan oluşur (Westerhoff, Aiken, ve ark., 1999; Westerhoff, Debroux, ve ark., 1999). Tablo 5'te görüldüğü gibi aynı koşullar altında $U V_{254}$ değişimlerinin önemli bir düşüşle sonuçlandığı görülmektedir. Elektron verici fonksiyonel gruplardaki elektron verici $\mathrm{UV}_{254}$ değeri düşük HA konsantrasyonlara göre daha yüksektir ve bu nedenle reaktivite eğilimleri ve aktiviteleri de daha yüksektir (Miao ve ark., 2008). DOM'un hidrofobik fraksiyonu olan hümik asit konsantrasyonunun artması ile THM konsantrasyonlarında artış olsa da oksidasyon ara ürünlerinde bu artış gözlenmez.

\subsection{Başlangıç pH'sının Katalitik Ozonlamaya Etkisi}

Çözeltinin başlangıç $\mathrm{pH}$ değeri $\mathrm{OH}$ konsantrasyonunu doğrudan etkilemese de asit ayrışma sabitini (pKa) ve katalizör yüzeyini etkilemektedir (Pirgalığlu Özbelge, 2009). Başlangıç $\mathrm{pH}$ değeri, ozonun bozunması ve dolayısıyla katalitik ozonlama süreci üzerinde olağanüstü bir etkiye sahiptir. Katalitik ozonlama prosesinde başlangıç $\mathrm{pH}$ değerinin THMOP parametresi üzerindeki etkisi Şekil 4'de incelenmiştir.

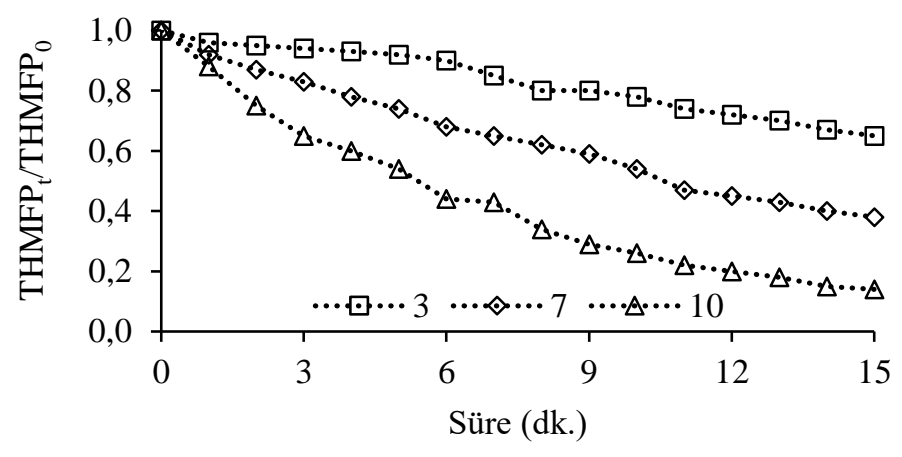

Şekil 4 Başlangıç pH'sına bağlı olarak THMOP azalımı ([DKP] $=0.050 \mathrm{~g} / \mathrm{L},\left[\mathrm{O}_{3}\right]=10 \mathrm{mg} / \mathrm{L},[\mathrm{HA}]=10 \mathrm{mg} / \mathrm{L}, \mathrm{n}=600 \mathrm{rpm}$,

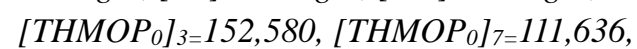
$\left[\text { THMOP}_{0}\right]_{10=151,844)}$

Şekil 4'te görüldüğü gibi, başlangıç pH değerinin artmasıyla birlikte THMOP'de azalmaktadır. Katalitik ozonlama ile THMOP azaltma verimliliği pH 3'te \%35'ten pH 10'da \%86'ya kadar artmıştır. Çözeltinin $\mathrm{pH}$ değerine bağlı olarak oluşan DYÜ türleri ve konsantrasyonları değişiklik göstermektedir. Genellikle düşük $\mathrm{pH}$ değerlerinde oksidasyon ara ürünü olarak bilinen HAA'ların, yüksek $\mathrm{pH}$ değerlerinde ise THM'lerin oluşumu artmaktadır (Hong ve ark., 2013). Bunun sebebi düşük $\mathrm{pH}$ değerlerinde zincirleme katalitik ozonlama reaksiyonlarının tamamlanmaması dolayısıyla organik maddenin son ürüne 
okside edilememesi ve istenmeyen ara ürünlerin oluşmasıdır. Şekil 4'te gösterildiği gibi, bazik $\mathrm{pH}$ değerlerinde yüksek THMOP azaltma verimi gözlemlenmiştir. Katalitik ozonlama proseslerinde, çözeltinin $\mathrm{pH}$ değeri katalizörün $\mathrm{pH}_{\mathrm{PZC}}$ değerine yaklaştığında $\mathrm{OH}$ aktivitesinde dikkate değer bir artış gözlenmektedir.

Düşük pH değerlerinde HA, zayıf asidik fonksiyonel gruplar içermektedir ve bu gruplar (karboksil ve fenolik) iyonize olmayan boşlukları nedeniyle daha fazla adsorptiftir (Daifullah ve ark., 2004; Zouboulis ve ark., 2003). Düşük pH değerlerinde HA, karboksilik ve fenolik grupların varlığından dolayı negatif olarak yüklenmekte iken ICP katalizörünün yüzeyi ise pozitif olarak yüklenmektedir. Katalizör yüzeyine $\mathrm{H}^{+}$iyonlarının tutunmasından dolayı katalizörün yüzey asitliği artmaktadır. Katalizör yüzeyinde negatif yüklü olan HA ile pozitif yüklü zayıf asitler arasında iyon eşleşmesi meydana gelmektedir. $\mathrm{pH}$ değeri yükseldikçe iyon eşleşmesi devam etmektedir. Katalitik ozonlama proseslerinde katalizör yüzeyinde kirleticinin adsorpsiyonunun yanı sıra ve hatta daha önemli olarak ozonun bozunması daha önemlidir. Düşük pH değerlerinde bu nedenle ozon bozunumu ve buna bağlı olarak radikal oluşumu azalmaktadır.

HA üzerindeki fonksiyonel gruplar yüksek pH değerlerinde bozuldukça HA bozulmasında azalma gözlenmektedir.

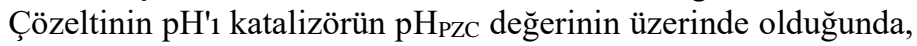
tüm katalizör yüzeyinin yükü negatif olmakta ve katyon değişim reaksiyonları meydana gelmektedir. $\mathrm{PH}_{\mathrm{PZC}}$ değerinin altında ise katalizör yüzeyi pozitif yüklenmekte ve anyonik değişim reaksiyonları gerçekleşmektedir. Çözeltinin $\mathrm{pH}$ değeri $\mathrm{pH}_{\mathrm{PZC}} \mathrm{ye}$ eşit olduğunda DKP katalizörü ile HA arasında elektrostatik etkileşim meydana gelmektedir. Bu çalışmada kullanılan DKP katalizörünün $\mathrm{pH}_{\mathrm{PZC}}$ değeri 7,13'tür ve bu değerin üzerinde HA adsorpsiyonu, HA ile katalizör yüzeyi arasındaki elektrostatik iterasyonun artması nedeniyle zorlaşmaktadır (Yang ve ark., 2020). Bu nedenle, katalitik ozonlama reaksiyonların çözelti katalizör arayüzeyinde gerçekleştiği düşünülmektedir. Tablo 6'da başlangıç $\mathrm{pH}$ değişimine bağlı olarak DOM konsatrasyonlarındaki ve fraksiyonlarındaki değişim gösterilmiştir.

Tablo 6 Başlangıç pH'ına bağlı olarak ÇOK, $U V_{220}, U V_{254}$ ve $U V_{272}$ değişimi $\left([\mathrm{DKP}]=0.050 \mathrm{~g} / \mathrm{L},\left[\mathrm{O}_{3}\right]=10 \mathrm{mg} / \mathrm{L},[\mathrm{HA}]=10\right.$ $m g / L, n=600 \mathrm{rpm}$ ).

\begin{tabular}{lcccc}
\hline $\mathbf{p H}$ & $\mathbf{C O K}, \boldsymbol{\%}$ & $\boldsymbol{\Delta} \mathbf{U V 2 2 0}, \boldsymbol{\%}$ & $\mathbf{- \Delta} \mathbf{U V ~ V 2 5 4}_{\mathbf{2 5}} \boldsymbol{\%}$ & $\boldsymbol{- \Delta} \mathbf{\Delta V _ { 2 7 2 } , \boldsymbol { \% }}$ \\
\hline 3 & 60 & 4,50 & 8,73 & 3,30 \\
7 & 76 & 32,48 & 21,32 & 3,49 \\
10 & 99 & 60,72 & 61,12 & 62,61 \\
\hline
\end{tabular}

Başlangıç pH'sı, dezenfeksiyon amacıyla yapılan klorlama sonrası ara ürün oluşumunu belirleyen önemli bir faktördür. Stabilize olmayan ara ürünlerin oluşumu bazik pH'larda azalır (Alver ve ark., 2020). Artan $\mathrm{pH}$ ile oksidasyon ara ürünü oluşumunun azalması esas olarak organik madde halojenlerinin, hidrofobik fraksiyonlarla reaksiyonlarında etkili olmalarından kaynaklanmaktadır (Qi ve ark., 2018). Organik maddelerin hidrofilik fraksiyonları ile halojenlerle reaksiyonu, $\mathrm{pH}$ artışından etkilenmemektedir. Asidik ortamlarda ise bunun tersi geçerlidir.

\section{Sonuç}

Katalitik ozonlama deneyleri sırasında yüksek molekül ağırlıklı HA'ların alifatik ve aromatik yapısındaki değişimi e-ISSN: 2148-2683 katalizör yüzeyinde düşük moleküler ağırlıklı organik bileşiklere dönüştüğünün bir göstergesi olarak düşünülebilir. $\mathrm{Bu}$ sebeple $\mathrm{pH}$ 3-9 aralığında 0,025-0,100 g/L DKP katalizörlüğünde 6-12 mg/L ozon dozuyla 2,5-20 mg/L HA'nın $15 \mathrm{dk}$ boyunca parçalanması neticesinde organik maddenin bir kısmının son ürüne okside olduğu kalan kisminda klorla reaksiyonu sonucunda THMOP'nin \%15-86 oranında azaldığı tespit edişmiştir. Terminal dezenfektan olarak kullanılan klor ile katalitik ozonlama sonrası oluşan düşük molekül ağırlıklı NOM'lar arasındaki rekasiyonlar sonucunda farklı oksidasyon ara ürünlerinin de oluştuğu düşünülmektedir. Bu çalışmada, DKP katalizörlüğünde ozonlama prosesleri ile HA içeren model çözeltilerin organik yapısındaki değişimler ve THMOP kapsamlı bir şekilde araştırılarak önemli kazanımlar elde edilmiştir. Çalışma sonuçları, ozonun DYÜ öncüllerinin uzaklaştırılmasındaki rolünün daha iyi anlaşılmasına taniyacaktır.

\section{Teşekkür}

Bu çalışma Aksaray Üniversitesi BAP Koordinasyon Birimi tarafindan 2015-050 nolu 68003-Doktora Projesi olarak desteklenmiştir.

\section{Kaynakça}

Alver, A., Baştürk, E., Kılıç, A. (2020). Development of adaptive neuro-fuzzy inference system model for predict trihalomethane formation potential in distribution network simulation test. Environmental Science and Pollution Research, 1-13.

Alver, A., Karaarslan, M., Kılıç, A. (2016). The catalytic activity of the iron-coated pumice particles used as heterogeneous catalysts in the oxidation of natural organic matter by $\mathrm{H} 2 \mathrm{O} 2$. Environmental technology, 37(16), 2040-2047.

Bakanlığı, T. C. S. (2012). Insani Tüketim Amaçlı Sular Hakkında Yönetmelik. (TSE-266). Ankara: T.C. Cumhurbaşkanlığı

Brezinski, K., Gorczyca, B. (2019). An overview of the uses of high performance size exclusion chromatography (HPSEC) in the characterization of natural organic matter (NOM) in potable water, and ion-exchange applications. Chemosphere, 217, 122-139.

Chi-Wang, L., Korshin, G. V., Benjamin, M. M. (1998). Monitoring DBP formation with differential UV spectroscopy. American Water Works Association. Journal, 90(8), 88 .

Daifullah, A., Girgis, B., Gad, H. (2004). A study of the factors affecting the removal of humic acid by activated carbon prepared from biomass material. Colloids and Surfaces A: Physicochemical and Engineering Aspects, 235(1), 1-10.

Davies, J.-M., Mazumder, A. (2003). Health and environmental policy issues in Canada: the role of watershed management in sustaining clean drinking water quality at surface sources. Journal of Environmental Management, 68(3), 273-286.

Gümüş, D., Akbal, F. (2017). Catalytic Ozonation for The Removal of Humic Acid in Water with Iron Coated Zeolite (ICZ). Nevşehir Bilim ve Teknoloji Dergisi, 6, 424-430. 
Hayward, K. (1998). Drinking water contaminant hit-list for US EPA. Water, 21(4).

Hong, H., Xiong, Y., Ruan, M., Liao, F., Lin, H., Liang, Y. (2013). Factors affecting THMs, HAAs and HNMs formation of Jin Lan Reservoir water exposed to chlorine and monochloramine. Science of the Total Environment, $444,196-204$.

Hong, S., Elimelech, M. (1997). Chemical and physical aspects of natural organic matter (NOM) fouling of nanofiltration membranes. Journal of membrane science, 132(2), 159-181.

International, A. (2004). Annual book of ASTM standards. ASTM International.

Kim, H.-C., Yu, M.-J., Han, I. (2006). Multi-method study of the characteristic chemical nature of aquatic humic substances isolated from the Han River, Korea. Applied geochemistry, 21(7), 1226-1239.

Kim, J. K., Alajmy, J., Borges, A. C., Joo, J. C., Ahn, H., Campos, L. C. (2013). Degradation of humic acid by photocatalytic reaction using nano-sized $\mathrm{ZnO} /$ laponite composite (NZLC). Water, Air, \& Soil Pollution, 224(11), 110 .

Lai, C., Chen, C.-Y. (2001). Removal of metal ions and humic acid from water by iron-coated filter media. Chemosphere, 44(5), 1177-1184.

Lai, C., Lo, S., Chiang, H. (2000). Adsorption/desorption properties of copper ions on the surface of iron-coated sand using BET and EDAX analyses. Chemosphere, 41(8), 12491255 .

Li, C., Wang, D., Li, N., Luo, Q., Xu, X., Wang, Z. (2016). Identifying unknown by-products in drinking water using comprehensive two-dimensional gas chromatographyquadrupole mass spectrometry and in silico toxicity assessment. Chemosphere, 163, 535-543.

Li, C., Wang, D., Xu, X., Wang, Z. (2017). Formation of known and unknown disinfection by-products from natural organic matter fractions during chlorination, chloramination, and ozonation. Science of the Total Environment, 587, 177-184.

Maurice, P. A., Pullin, M. J., Cabaniss, S. E., Zhou, Q., Namjesnik-Dejanovic, K., Aiken, G. R. (2002). A comparison of surface water natural organic matter in raw filtered water samples, XAD, and reverse osmosis isolates. Water Research, 36(9), 2357-2371.

Miao, H., Tao, W., Cui, F., Xu, Z., Ao, Z. (2008). Kinetic study of humic acid ozonation in aqueous media. CLEAN-Soil, Air, Water, 36(10-11), 893-899.

Pirgalığlu, S., Özbelge, T. A. (2009). Comparison of noncatalytic and catalytic ozonation processes of three different aqueous single dye solutions with respect to powder copper sulfide catalyst. Applied Catalysis A: General, 363(1), 157163.

Qi, W., Zhang, H., Hu, C., Liu, H., Qu, J. (2018). Effect of ozonation on the characteristics of effluent organic matter fractions and subsequent associations with disinfection byproducts formation. Science of the Total Environment, 610, 1057-1064.
Rice, E. W., Baird, R. B., Eaton, A. D., Clesceri, L. (2012). Standard methods for the examination of water and wastewater. American Public Health Association, Washington, DC.

Sadrnourmohammadi, M., Brezinski, K., Gorczyca, B. (2020). Ozonation of natural organic matter and aquatic humic substances: the effects of ozone on the structural characteristics and subsequent trihalomethane formation potential. Water Quality Research Journal, 55(2), 155-166.

Świetlik, J., Dąbrowska, A., Raczyk-Stanisławiak, U., Nawrocki, J. (2004). Reactivity of natural organic matter fractions with chlorine dioxide and ozone. Water Research, 38(3), 547558.

Westerhoff, P., Aiken, G., Amy, G., Debroux, J. (1999). Relationships between the structure of natural organic matter and its reactivity towards molecular ozone and hydroxyl radicals. Water Research, 33(10), 2265-2276.

Westerhoff, P., Debroux, J., Aiken, G., Amy, G. (1999). Ozone-induced changes in natural organic matter (nom) structure. Ozone: science \& engineering, 21(6), 551-570.

Yang, H., Wu, X., Su, L., Ma, Y., Graham, N. J., Yu, W. (2020). The $\mathrm{Fe}-\mathrm{N}-\mathrm{C}$ oxidase-like nanozyme used for catalytic oxidation of NOM in surface water. Water research, 171, 115491.

Yuan, L., Shen, J., Chen, Z., Liu, Y. (2012). Pumice-catalyzed ozonation degradation of $\mathrm{p}$-chloronitrobenzene in aqueous solution. Applied Catalysis B: Environmental, 117, 414-419.

Zouboulis, A. I., Jun, W., Katsoyiannis, I. A. (2003). Removal of humic acids by flotation. Colloids and Surfaces A: Physicochemical and Engineering Aspects, 231(1), 181-193. 